\title{
Development of Strengthened Bundle High Temperature Superconductors*
}

\author{
By \\ J. W. Lue and M. S. Lubell \\ Oak Ridge National Laboratory \\ J. A. Demko \\ Oak Ridge Associated Universities/ \\ Oak Ridge Institute for Science and Education \\ RECEIVED \\ SEP 231997 \\ O STI \\ M. Tomsic \\ Plastronic, Inc \\ Troy, $\mathrm{OH} 45373$ \\ U. Sinha \\ Southwire Company \\ Carollton, GA 30119 \\ Presented at the \\ CEC/ICMC \\ Cryogenic Engineering Conference \\ Portland, Oregon \\ July 28 - August 1, 1997 \\ Prepared for the

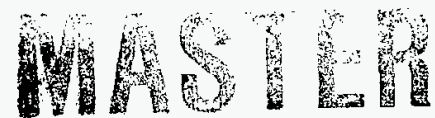 \\ U.S. Department of Energy \\ Office of Energy Efficiency and Renewable Energy \\ Office of Utility Technology \\ (EB 5001000 )

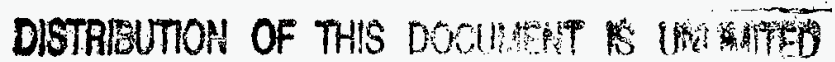 \\ Prepared at \\ Oak Ridge National Laboratory \\ Post Office Box 2008 \\ Oak Ridge, TN 37831-6285 USA

\section{Managed by \\ LOCKHEED MARTIN ENERGY RESEARCH, INC. for the \\ U.S. DEPARTMENT OF ENERGY \\ under contract DE-AC05-96OR22464}

* Research sponsored by the U.S. Department of Energy, Office of Energy Efficiency and Renewable Energy, Office of Utility Technology-Superconductivity Program. This research was supported in part by the ORNL Postdoctoral Research Associates Program, administered jointly by the Oak Ridge Institute for Science and Education and ORNL, under contract DE-AC05-960R22464 with Lockheed Martin Energy Research Corporation, Inc. 


\section{DISCLAIMER}

This report was prepared as an account of work sponsored by an agency of the United States Government. Neither the United States Government nor any agency thereof, nor any of their empioyees, makes any warranty, express or implied, or assumes any legal liability or responsibility for the accuracy, completeness, or usefulness of any information, apparatus, product, or process disclosed, or represents that its use would not infringe privately owned rights. Reference herein to any specific commercial product, process, or service by trade name, trademark, manufacturer, or otherwise does not necessarily constitute or imply its endorsement, recommendation, or favoring by the United States Government or any agency thereof. The views and opinions of authors expressed herein do not necessarily state or reflect those of the United States Government or any agency thereof. 


\title{
DEVELOPMENT OF STRENGTHENED BUNDLE HIGH TEMPERATURE SUPERCONDUCTORS
}

\author{
J. W. Lue ${ }^{1}$, J. A. Demko ${ }^{1}$, M. S. Lubell ${ }^{1}$, M. Tomsic ${ }^{2}$, and U. Sinha ${ }^{3}$ \\ ' Oak Ridge National Laboratory \\ Oak Ridge, TN 37831-8071. USA \\ ${ }^{2}$ Plastronic, Inc. \\ Troy, OH 45373, USA \\ ${ }^{3}$ Southwire Company \\ Carrollton, GA 30119, USA
}

\begin{abstract}
In the process of developing high temperature superconducting (HTS) transmission cables, it was found that mechanical strength of the superconducting tape is the most crucial property that needs to be improved. It is also desirable to increase the current carrying capacity of the conductor so that fewer layers are needed to make the kilo-amp class cables required for electric utility usage. A process has been developed by encapsulating a stack of $\mathrm{Bi}-2223 / \mathrm{Ag}$ tapes with a silver or non-silver sheath to form a strengthened bundle superconductor. This process was applied to HTS tapes made by the Continuous Tube Forming and Filling (CTFF) technique pursued by Plastronic Inc. and HTS tapes obtained from other manufacturers. Conductors with a bundle of 2 to 6 HTS tapes have been made. The bundled conductor is greatly strengthened by the non-silver sheath. No superconductor degradation as compared to the sum of the original critical currents of the individual tapes was seen on the finished conductors.
\end{abstract}

\section{INTRODUCTION}

Because of the fundamental processing requirements, ceramic High Temperature Superconductors (HTS) are made in the form of thin tape that is very fragile and carries a current of only tens to a few hundred amperes each. In the process of developing HTS transmission cables, it was found that the mechanical strength of the superconducting tape is the most crucial property that needs to be improved ${ }^{1}$. It is also desirable to increase the current carrying capacity of the conductor so that fewer layers are needed to make the kiloamp class cables required for electric utility usage. 
Plastronic Inc. has been pursuing a Continuous Tube Forming and Filling (CTFF) approach to make $\mathrm{Bi}-2223 / \mathrm{Ag}^{2}$ tapes $^{2}$. As an extension of this technique, a sneath is wrapped around a bundle of HTS tapes to form a strengthened, higher current carrying superconductor. Thus, a process is being developed to make the $\mathrm{Bi}-2223 / \mathrm{Ag}$ tapes into a workable, higher current carrying conductor for large scale applications. Examples of the strengthened bundle superconductors and their electrical and mechanical test results are presented.

\section{ENCAPSULATED BUNDLE SUPERCONDUCTOR}

A stack of HTS tapes are bundled together, encapsulated with a silver or non-silver sheath by a continuous tube forming process, and sintered to finish the superconductor forming process. A large current carrying conductor is achieved with the stacking of multiple HTS tapes. Different strengthening metal, both silver and non-silver, can be used as the sheath material to wrap around the stack to form a robust conductor. Bundle superconductors of up to $6 \mathrm{HTS}$ tapes have been made. Figure 1A shows the cross section of a 3-tape bundle conductor consisting of $\mathrm{Bi}-2223 / \mathrm{Ag}$ tapes made by the CTFF approach pursued by Plastronic Inc. Each HTS tape contains 8 filaments running the width of the tape. The superconductors of the finished conductor are well protected from external abuses and possible damages caused by liquid nitrogen penetration.

The unique procedure of sintering after the encapsulation makes the present technique also suitable to make bundle conductors out of finished HTS tapes. No undesirable soldering process that may damage the HTS tapes is used. Figure 1B shows the example of a 3-tape bundle conductor consisting of commercially available $\mathrm{Bi}-2223 / \mathrm{Ag}$ tapes (T-tapes) acquired from a third party tape manufacturer.

The present bundling and encapsulating approach is quite flexible. Depending on the application, sheathing material of different strength and thermal or electrical properties can be used. The non-silver sheath may provide enough resistance so that no additional insulation is needed for some applications. Different stacking arrays of the HTS tapes can be arranged. For ac applications, resistive barriers can be inserted between the HTS tapes to reduce the ac losses.

\section{MECHANICAL STRENGTH OF THE BUNDLE CONDUCTOR}

Mechanical strength of the CTFF- and T-HTS tapes and examples of the encapsulated bundle conductors have been measured at room temperature. The results are summarized in Table 1. For the HTS tapes the averages from several samples are listed. The yield stress (YS) was taken at a strain of $0.2 \%$. The elongation percent was measured after the sample broke into two halves. The percent increase of the sum of the length of the pieces over the original length are listed as the elongation $\%$.

The CTFF tape has a slightly better ultimate tensile strength (UTS) (60 Mpa) than the T-tape (45 Mpa) and a slightly higher elongation \%. The UTS of the bundle conductors are (134-153 Mpa) much higher than the HTS tapes. The elongation test resulted in the bundle conductor having more than an order of magnitude higher elongation \% before breaking. The more brittle inner HTS tapes probably broke before the sheath. The measured mechanical properties of the bundle conductors seem to be dominated by the characteristics of the sheath. Thus, desirable mechanical properties of a bundle conductor can be achieved with the proper choice of the sheath material and thickness. 

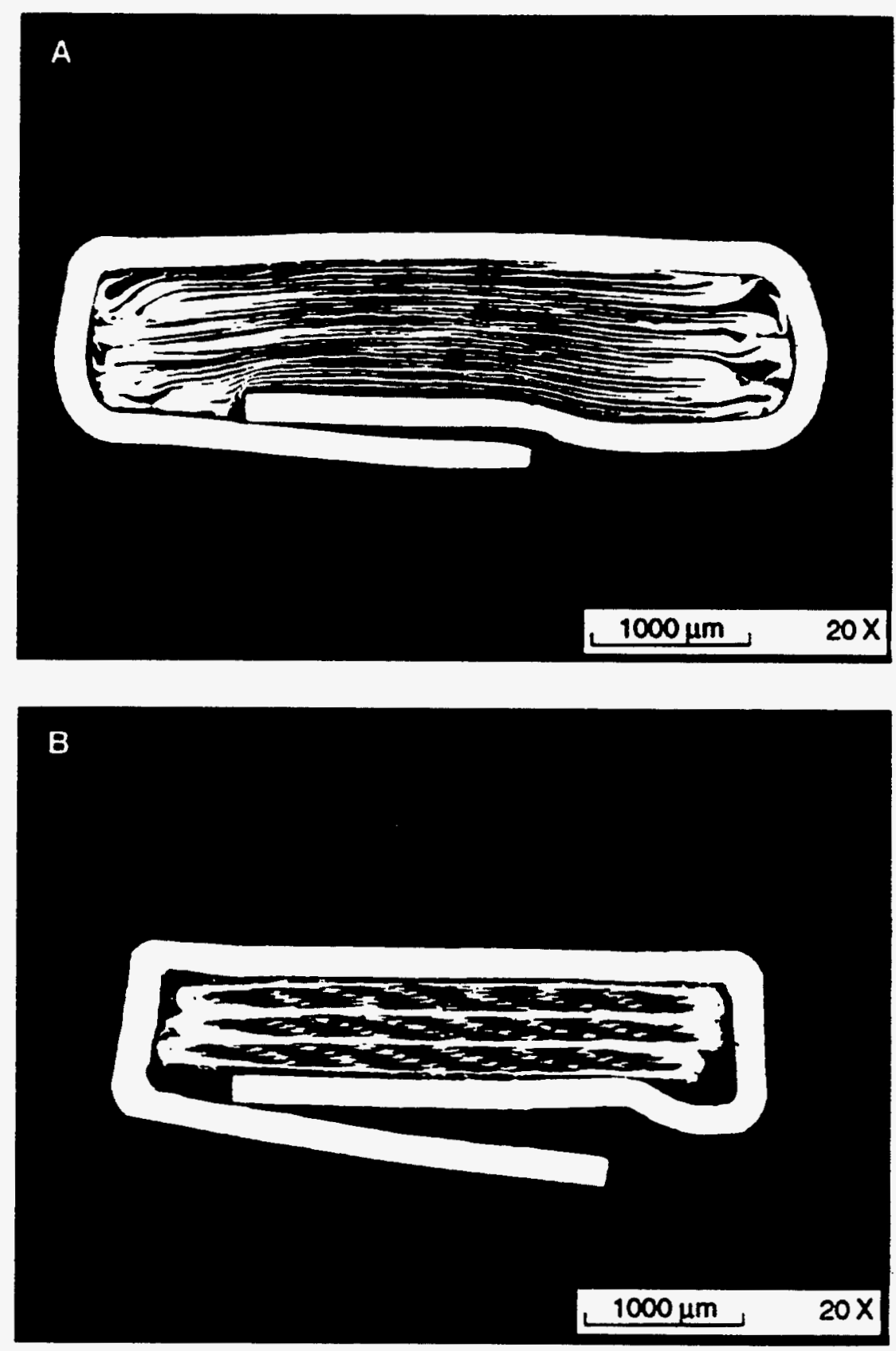

Figure 1. Cross sectional view of examples of encapsulated bundle superconductor. (A) a 3-tape bundle of CTFF tapes, (B) a 3-tape bundle of T-tapes.

Table 1. Mechanical properties of HTS tapes and sample bundle conductors

\begin{tabular}{|c|c|c|c|}
\hline Sample & $\begin{array}{c}\text { LTS } \\
(\text { Mpa } / k s i)\end{array}$ & $\begin{array}{c}\mathrm{YS} \\
\text { (Mpa/ksi) }\end{array}$ & $\begin{array}{c}\text { Elongation } \\
(\%)\end{array}$ \\
\hline CTFF-tapes & $60: 8.8$ & $55 / 8.0$ & 3.5 \\
\hline T-tapes & 456.5 & $+2 / 6.1$ & 1.0 \\
\hline A 3-tape bundle & $153: 22.2$ & $6+/ 9.3$ & 40 \\
\hline A 6-tape bundle & $13+19.5$ & $63 / 9.1$ & 30 \\
\hline
\end{tabular}




\section{BENDING TESTS OF THE BUNDLE CONDUCTOR}

\section{Bundle conductor with Plastronic Tapes}

DC I-V curves were measured on a bundle conductor made of three 8-filament Plastronic CTFF tapes encapsulated in a Ag-sheath. The bundle conductor has overall dimensions of $0.94 \mathrm{~mm} \times 5.9 \mathrm{~mm}$. The measurement was made in liquid nitrogen with the sample in straight length first. The conductor was then coiled onto a $2.54-\mathrm{cm}$ diameter holder, and the I-V curve was measured again. Figure 2 shows the two measured I-V curves. There is significant decrease in the current carrying capacity of the conductor after bending. The voltage taps were separated by $20 \mathrm{~cm}$. Thus, this conductor has a critical current, $I_{c}$ of $34.5 \mathrm{~A}$ in straight length and of $18.5 \mathrm{~A}$ when wrapped around a $2.54-\mathrm{cm}$ diameter holder. There is a $46 \%$ reduction in $I_{c}$ after the bending.

\section{Bundle Conductor with Third Party Tapes}

As was mentioned before, the present bundling and encapsulating technique can be applied to commercially finished HTS tapes. A sample was made with the T-tapes by encapsulating a 3-tape bundle with a non-silver sheath. An extensive study of the bending tolerance of this conductor was made by coiling it onto successively smaller diameter holders. Since the conductor sheath has one thickness on one side of the bundle (see Fig.1) and double thickness on the other side, this sample was cut into two halves and tested separately in different bending forms. One half was tested with the double sheath thickness on the ID of the winding and the other half was on the OD of the winding. A lay angle of

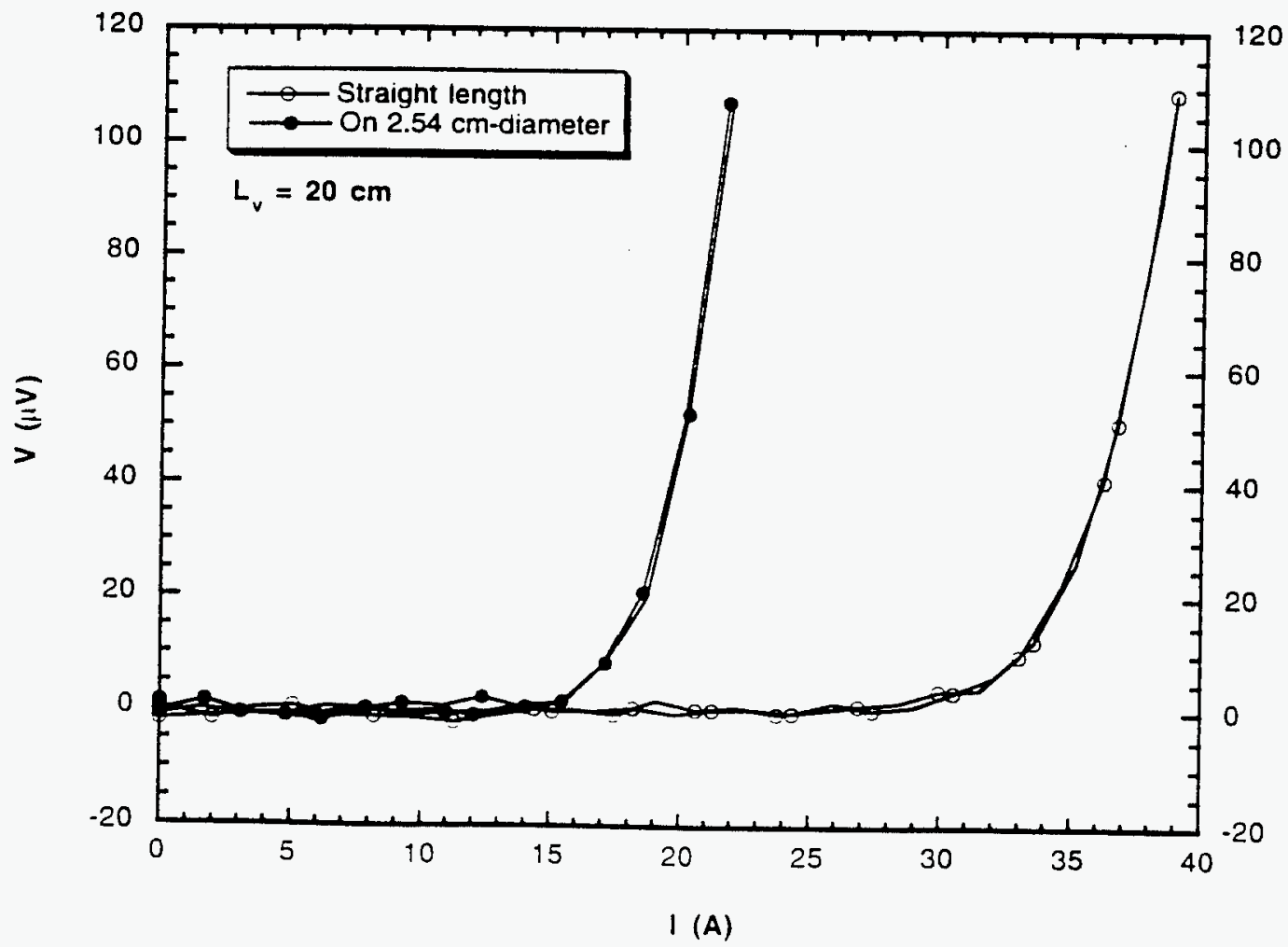

Figure 2. I-V curves of a 3-tape bundle of CTFF tapes in straight length and wrapping around a 2.54-cm diameter holder. 
$45^{\circ}$ was used in this series of tests. Figure $3 \mathrm{~A}$ shows the I-V curves of the half tested with the double sheath side on the ID of the winding. A gradual decrease in the current carrying capacity of the conductor was observed. Figure $3 \mathrm{~B}$ shows the I-V curves of the other half tested with the double sheath side on the OD of the winding. A similar but less severe decrease in the current carrying capacity was seen in this case.
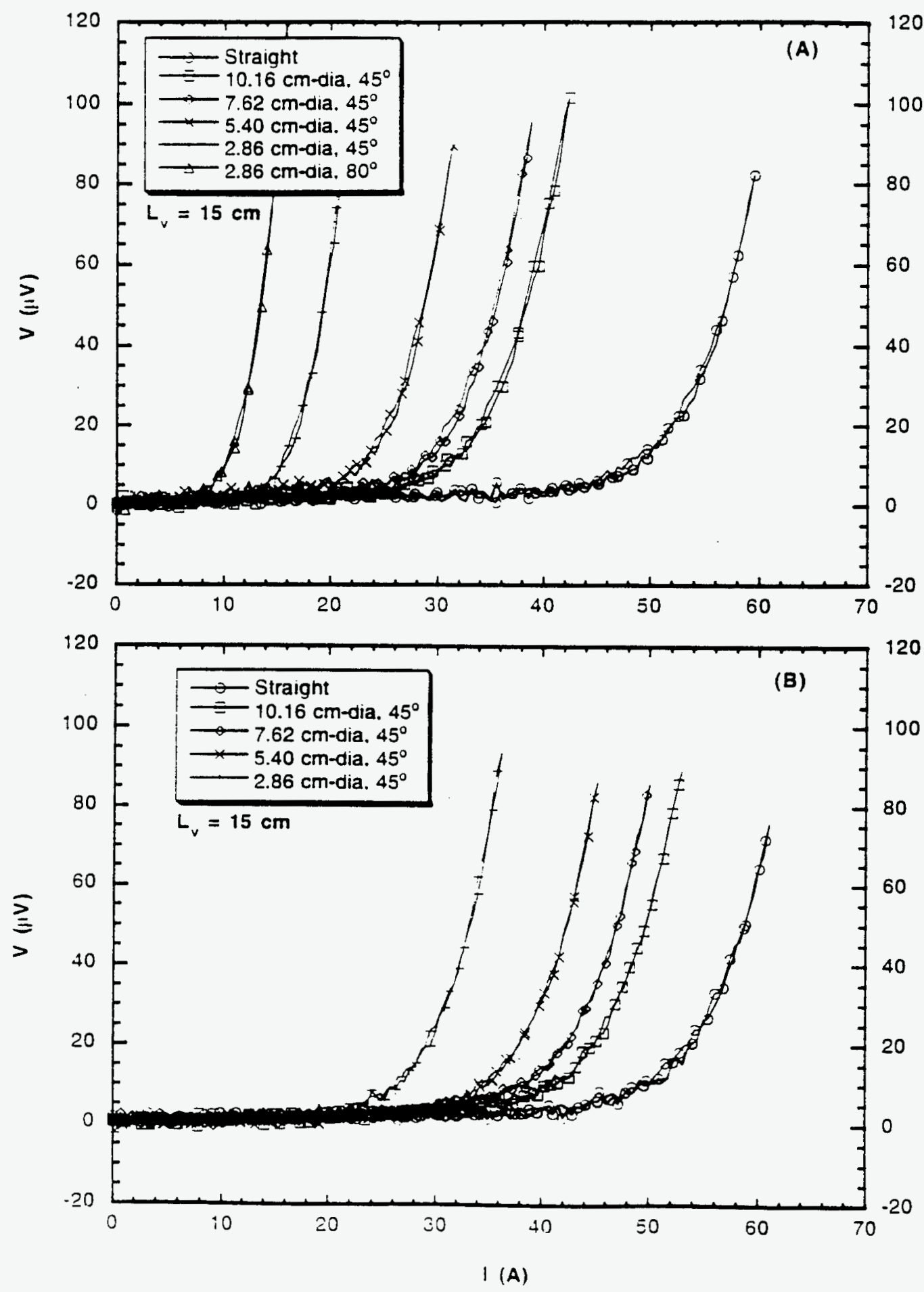

Figure 3. I-V curves of a 3-tape bundle of the T-tapes in straight length and wrapping around successively smaller diameter holders. (A) the double-sheath side was wound on the ID of the former. (B) the double-sheath side was wound on the OD of the former. 
Nearly identical critical currents of $51.4 \mathrm{~A}$ and $52.8 \mathrm{~A}$ were measured for the two halves of the sample in straight length. The as received tape has a nominal $\mathrm{I}_{\mathrm{c}}$ of $15.6 \mathrm{~A}$. Thus, the encapsulated bundle conductor has more than retained the original $I_{c}$ of the individual tapes.

The degradation of bending with the double sheath thickness on the ID of the winding were, however more severe than on the $\mathrm{OD}$ of the winding. For example, at the $7.62-\mathrm{cm}$ diameter bend the $I_{c}$ had dropped to $31.1 \mathrm{~A}$ in the former case but to $41.5 \mathrm{~A}$ for the latter case. Apparently, even though the conductors were bent on the same diameters, the degree of bending on the superconductors were different under these two conditions.

The average bending strain. $\varepsilon$ on a conductor bending to a radius, $R$ is given by

$$
\varepsilon=\frac{t / 2}{R} \sin \theta
$$

where the lay angle, $\theta$ is measured from the axis of the former and $t$ is the thickness of the conductor. The 3-HTS-tape bundle thickness is about $0.66 \mathrm{~mm}$, the sheath thickness is about $0.178 \mathrm{~mm}$ for a total conductor thickness of $1.194 \mathrm{~mm}$. Thus, the neutral plane was $0.597 \mathrm{~mm}$ from the ID of the conductor when it is bent. When the double-sheath thickness was on the ID of the winding, the thickness of the HTS tapes that was under tension was $0.419 \mathrm{~mm}$. When the double sheath thickness was on the OD, the thickness of the HTS tape that was under tension was $0.241 \mathrm{~mm}$, i.e. less superconductor was under tension in the latter case. By using these thickness' of the superconductor under tension as the $t / 2$ in Eq. (1), we calculated the bending strains of the superconductor under the two different bending cases. The strain levels were $74 \%$ higher when the double-sheath thickness was bent on the ID of the winding. Figure 4 shows the two sets of the measured $I_{c}$ as a function

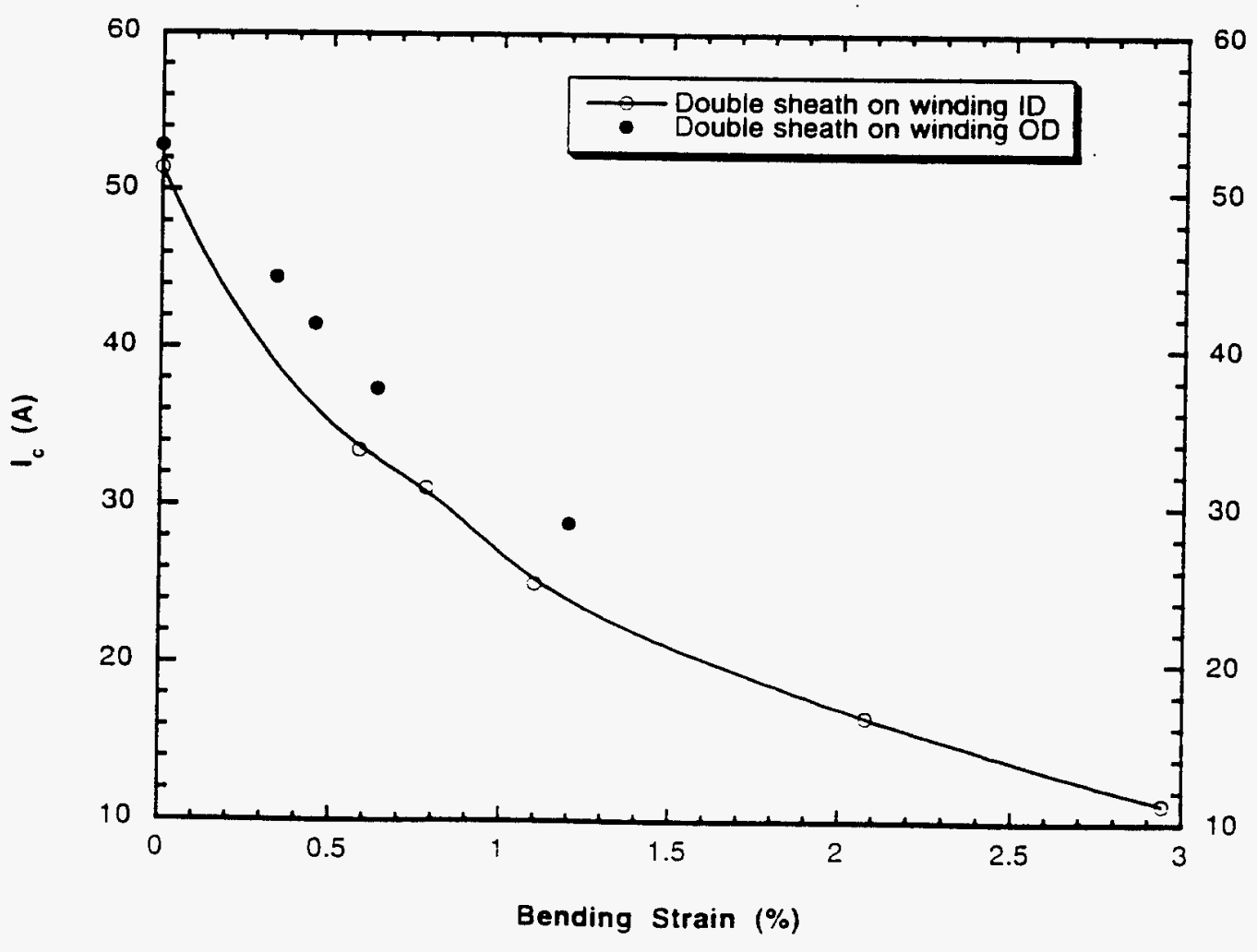

Figure 4. Critical currents as a function of bending strain for the conductor tested in Fig. 3. The strains were calculated with the thickness of the superconductor in tension only. 
of the bending tensile strains. The solid line curve is drawn through the set of data of the double-sheath side on ID. The two sets of data show a single trend of degradation. Thus, we conclude that the part of the superconductor that is under bending tension contributes to most of the degradation. Note that because no data was taken at strains less than $0.5 \%$ on this set of data, the linear drop indicated by the line connecting to the zero strain point may be fortuitous.

\section{Comparison with Single Tape Bending Results}

As a control, a piece of the T- tape was taken through the same re-sintering process as the bundle conductor. This tape was also tested for its bending tolerance by wrapping onto successively smaller diameter holders. I-V curves similar to those shown in Fig. 3 were measured.

The bending strain at each holder diameter was again calculated with Eq. (1). Note that since half of the superconductor was under tension (and half was under compression) the total tape thickness was used as the $t$ in this case. Figure 5 shows the reduced $I_{c}, I_{c} I_{c o}$ as a function of the bending strain for this re-processed tape and the bundle conductor described in above. The curve is a smooth fit through the data of the control tape. The bundle conductor data goes right along this curve. Thus, the $I_{c}$ degradation is due mostly to the tensile bending strain - the part of the superconductor that is subjected to bending tension, whether it is in a single tape or in a bundled form. More than $90 \%$ of the straight length $I_{c}$ can be retained if the tensile bending strain is limited to $0.2 \%$ for conductors made of this HTS tape.

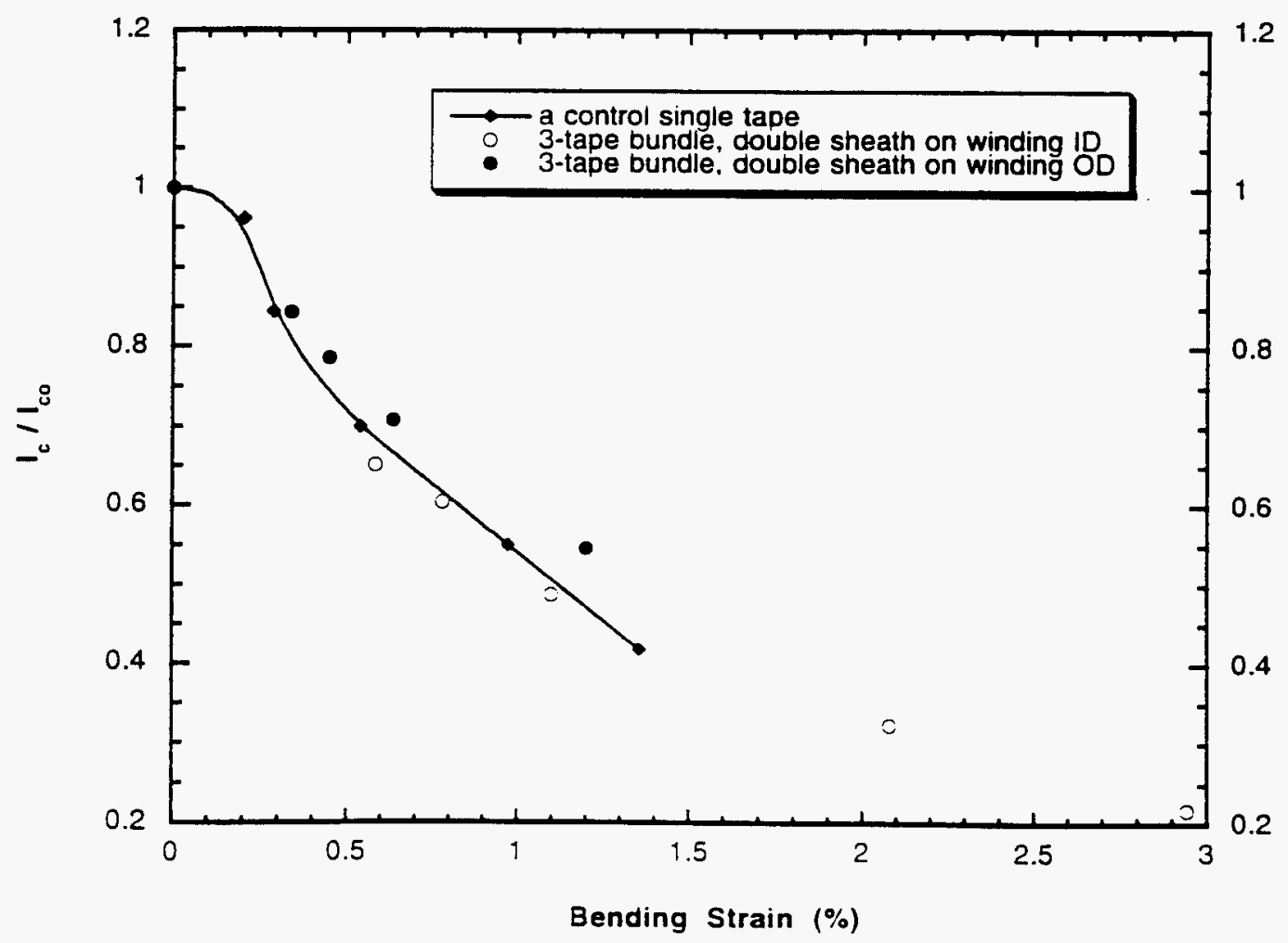

Figure 5. Reduced critical currents as a function of the bending strain for a control single tape and the bundle conductor tested in Fig. 3. 
If the conductor has to be bent into a given diameter, the bundle conductor will be subjected to higher bending strain and thus higher $I_{c}$ degradation because of its larger thickness. However, because it is mechanically stronger, it will be subjected to degradation caused by strains from handling and winding.

\section{CONCLUSION}

A process to strengthen the fragile HTS tapes has been developed by encapsulating a tape bundle with a metallic sheath. The same technique was used to make conductors with commercially finished HTS tapes as well as tapes that have not received a final heat treatment yet. When this technique was used for some finished tapes, the encapsulated bundle superconductor had more than retained the original $I_{c}$ of the individual tapes.

The encapsulated bundle conductor not only increases the current carrying capacity of the conductor but also improves its mechanical properties significantly. It is much easier to handle. The cabling and coil winding of such conductors will be more like that of conventional superconductors. Bending tolerance measurement on single control tape and the encapsulated bundle conductor showed similar $I_{c}$ degradation, due mostly to the part of the superconductor that is subjected to tension from bending.

The presently developed robust and high current carrying conductor should be very useful for large scale applications that use large bore windings, such as transformer, motor and generator, magnetic separation, energy storage, and MRI, etc.

\section{ACKNOWLEDGMENT}

This work was sponsored by the Office of Energy Efficiency and Renewable Energy, U. S. Department of Energy under contract DE-AC05-960R22464 with Lockheed Martin Energy Systems, Inc. The careful taking of the mechanical data by J. C. Tolbert is acknowledged.

\section{REFERENCES}

1. J. W. Lue, et al., "Test of two prototype high-temperature superconducting transmission cables", IEEE Trans. Applied Superconductivity, Vol. 7, No. 2, 302-305 (1997).

2. M. Tomsic and A. Sarkar, "Is low-cost bscco tape just around the corner?", Superconductor Industry, Vol. 10, No. 1, 18-23 (1997). 


\section{M98000119}

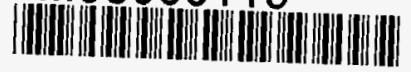

Report Number (14)CONF-970758--1

Publ. Date (11)

Sponsor Code (18) DOE/EE, XF

UC Category (19)

UC-1390, DOEIER 